\title{
STUDENT REFLECTIONS IN COURSE-BASED UNDERGRADUATE RESEARCH EXPERIMENT IN A FIRST-YEAR CIRCUITS COURSE
}

\author{
Yani Jazayeri \\ Schulich School of Engineering, University of Calgary \\ spjazaye@ucalgary.ca
}

\begin{abstract}
At the University of Calgary, we piloted a course-based undergraduate research experience in the first year circuits course. The intention was to provide authentic learning experiences, with the ultimate goal of fostering deep learning in the students. Using qualitative coding, these reflections were analyzed with a framework from self-determination theory to understand the student learning and motivation throughout the experience. There were 10 themes that emerged, categorized within the three elements of the theoretical framework: competence, relatedness, and autonomy.
\end{abstract}

Keywords: electrical engineering : student reflections : Course-based undergraduate research

\section{INTRODUCTION}

In [1], it is suggested that "students will benefit from an early introduction to research by learning to think critically about existing knowledge, developing the ability to ask researchable questions, exploring possible solutions, and using evidence as they analyze their work." To develop better critical thinking and problem-solving skills in our first-year engineering students, we are implementing a course-based undergraduate research experience in our first-year, common core, electrical circuit course.

This experience is viewed through the lens of experiential learning, meaning the research experiences will include (i) developing a question, (ii) becoming aware that there are different research methodologies and applying one, and (iii) sharing findings. The students would also have opportunities to (a) critically reflect on learning and (b) articulate skills developed/developing through the process.

In [1] and [2], the criteria for course-based undergraduate research is stated as the following:

- Research is embedded into the course curriculum.

- All students engage in the research project.

- Students work collaboratively on the project.

- Research projects introduce students to the research methodology of the discipline.

- Outcomes of the research are unknown. (i.e. unlike typical engineering problems where are the right and wrong answers, the research project exposes students to the idea of ambiguity)

- Student outcomes of the research are communicated in some manner (beyond the classroom).

- Incorporates student critical reflection.

The authors implemented an undergraduate research experience in Summer 2020 that incorporated most of the above criteria. This experience was carried out in a firstyear circuits course, a compulsory part of the engineering program at the authors' University. At the end of the semester, students were asked to reflect on their learnings during this exercise. Using qualitative coding, these reflections were analyzed with a framework from selfdetermination theory [3] to understand the student learning and motivation throughout the semester. Based on students' reflections, 10 different themes were formed within the three components of self-determination theory: competence, relatedness, and autonomy.

This paper will provide insights into the student learning experience in course-based undergraduate research experiment. This will hopefully provide readers with ideas for implementing and improving their own undergraduate research experiments.

\section{COURSE-BASED UNDERGRAdUATE RESEARCH (CURE)}

CURE's importance is described in [4] by stating its significance in allowing a curriculum to expand by providing research opportunities to all students. The study highlights that CURE is not only an expansion to the curriculum but is also responsible for introducing students to the research methodology of the discipline while enforcing collaboration amongst researching students. The uniqueness of this style is to impose to students that the research outcomes will be unknown, however student outcomes are to be expressed in some way. This is especially effective to administer open-ended critical thinking where learners are encouraged to develop 
confidence in their research and arguments pertaining to the subject.

Incorporating CURE into first year courses has tremendous benefit with exposing students to the methodologies of research while providing a thrill for learning. This is further aided with the ability to ask questions pertaining to the subject of interest and having the tools to find and discover potential answers while using evidence to analyze the effectiveness of their research and work. Teaching with this style in introductory first year courses enhances the student's learning experience throughout their undergraduate academic careers and better prepares them to handle problems later in their careers.

\subsection{Learning Outcomes from CURE}

The authors in [5] delve into CRUE by demonstrating how undergraduate research experience can be made more productive. The study focusses on the importance of problem analysis in engineering and how it simply isn't enough to solve mathematical problems to engage the creative aspect of the engineering mind. It was noted that students participating in undergraduate research were able to develop problem analysis skills by also developing investigative skills and communication skills. However, it is to be noted that a specific style of research can only engage this type of learning: open-ended research. This further supports the points made in [4] where student outcomes will be expressed, but research outcomes are to be unknown. This is further strengthened when the undergraduate researcher is asked to present their findings and work in some manner as opposed to writing a paper. This method is noted by the authors in [5] to increase student participation as well as making research more productive by ensuring students find unique answers to "real world" problems they are tasked with.

\subsection{Incorporating CURE with Introductory Electronic Circuits}

In [6], the authors integrated the social responsibility of engineers within their introductory circuits course at the University of San Diego. In their implementation, students were encouraged to get away from the typical math-heavy nature of first year engineering. They were able to accomplish this by introducing three modules within their course, with each one placing a unique emphasis on the engineering role within society.

The importance of freshman engineering retention and its correlation to deploying a multi-faceted approach to Electrical Engineering is emphasized in [7]. This study explores the notion that students must engage in a variety of activities that will introduce them to their peers and develop a confidence to use the resources that are available to them. This idea is further explored in this study by suggesting that students should also be introduced to the world of Electrical Engineering rather than just what is taught within the university. This can include events that are ongoing within the ECE (Electrical and Computer Engineering) world or innovations that excite electrical engineers.

\section{CURE IN ENGG 225}

In summer 2020, with all classes moved online due to COVID-19 pandemic, the first iteration of CURE was rolled out in our introductory circuits course. Students were asked to perform the following three mini-projects:

\subsection{Project 1}

For this project, students were asked to research the following topics and present their findings in a short paper (2 pages or less):

- What are conflict minerals, and which minerals are used in electronic devices

- Estimate the amount of conflict minerals used in your cell phone

- What steps (if any) are the manufacturers of your cell phone taking to reduce the amount of conflict material used in your device?

\subsection{Project 2}

For this project, students were asked to research the following topics and present their findings in a short presentation (5 minutes or less):

- An innovative electrical engineering news story or a social cause related to electrical engineering,

- How this story relates to a topic from ENGG 225

\subsection{Project 3}

For this project, students were asked to perform the following and present their findings in a short paper (2 pages or less):

- Record (take a picture of) the voltage, current and power ratings for 3 household devices and/or appliances.

- Using calculations, demonstrate how these values align or differ from what you learned in ENGG 225. If any differences are observed, explain them.

- Explain the importance of the power, current, and voltage ratings of that household item.

\section{METHODOLOGY}

\subsection{Theoretical Framework: Self- Determination Theory}

Motivation was chosen as the theoretical framework for evaluating the CURE project as it aligns with the rationale behind offering this exercise in the first place. 
There are many theories on motivation, from needsbased theories such as Maslow's hierarchy of needs, to process-based theories such as expectancy and reinforcement theories [8]. In educational settings however, it has been found that the use of selfdetermination theory (SDT) is productive as it provides guidance on the environment a teacher can foster to support student motivation [9].

Ryan and Deci are the primary thought leaders behind SDT, and they describe it as "an approach to human motivation and personality that uses traditional empirical methods while employing an organismic metatheory that highlights the importance of humans' evolved inner resources for personality development and behavioral selfregulation" [10]. The theory outlines three innate psychological needs for self-motivation and positive internal processes: the needs for competence, relatedness, and autonomy.

The important element of the SDT is that all three of these needs work in conjunction and would not be effective independently. When all three are working in conjunction, this is when an individual can achieve the greatest sense of well-being, or "eudaimonia" [10]. For example, autonomy increases intrinsic motivation, however intrinsic motivation is more likely to be effective when individuals feel a sense of security through their relatedness with others [10]. Autonomy in educational settings is particularly important, where teachers who support autonomous learning environments improve their students' intrinsic motivation, curiosity and desire for challenge [10].

As all three elements are basic needs, the theory does not "focus on the varying strength of needs but instead focus[es] on concepts resulting from the degree to which the needs have been satisfied versus thwarted" [2]. For example, an activity such as a prescribed lab activity might satisfy competence and relatedness, however it thwarts the need for autonomy. In educational settings, it is important to do our best to engage in activities which best satisfy at least some part of all three needs.

\subsection{Data Collection}

At the end of the semester, students were asked to reflect on the CURE project on the project. This reflection included four open-ended questions such as What were the best aspects of these projects? How can the projects be improved? Did these projects help you gain a deeper understanding of the course material better? Should these projects be lessened, kept as it is, or expanded?

Qualitative analysis of the results is presented in the following sections. A quick quantitative analysis of the survey results showed that all participants agreed that the projects helped them gain a better understanding of the material (to varying degrees). All participants also agreed that the projects should be kept as they are.

\subsection{Data Analysis}

Deductive thematic analysis was used to analyze the student reflections and assignments. We followed Braun and Clarke's method for thematic analysis, which they describe as "a method for identifying, analyzing and reporting patterns within data" [11].

Our approach to thematic analysis is routed in constructionism, in which we aim to report the experience and reality of the participants, which we believe to be socially constructed. With this approach, we can focus on the sociocultural context of the projects, and theorize about the structural conditions the program was able to achieve. In our analysis, we mainly focused on semantic themes where we are looking at the words used by participants at their surface meanings, without too much interpretation beyond their meaning [11].

We followed the steps of thematic analysis, as laid out by Braun and Clarke [11]: familiarize ourselves with data; generate initial codes; search for themes; review themes; define and name themes; and produce the report. As we used deductive analysis with the self-determination theory, we also grouped our themes under the categories of competence, relatedness, and autonomy.

\section{Results}

From the thematic analysis, there were 10 themes that emerged, categorized within the three elements of the theoretical framework: competence, relatedness, and autonomy. Those themes were:

- Competence: Technical skills, self-confidence, preparedness for future, deeper knowledge, analytical skills, fair competition

- Relatedness: Sense of belonging

- Autonomy: self-directed learning, freedom of choice, self-advocacy

In our discussion of the results below, we have included quotes from the student reflections included to illustrate each of the themes.

\subsection{Competence}

Through our analysis, competence was the most popular element among the three elements of the SDT. The need for Competence referred to when the students felt satisfaction and their need to experience confidence in achieving desired outcome [12]. According to Irvine, "satisfying the need for competence means experiencing mastery" and being recognized for such expertise [13].

5.1.1. Technical Skills. This was the most commonly addressed theme among students' surveys. Through these projects, students greatly improved their technical skills on real world circuit concepts. One student said: "The last project is helping me understand the implementation of basic circuit ideas and concepts in the real world. Because we have to calculate power and current and explain why 
there are typically discrepancies between real world values and theoretical values." They clearly identified the differences between theoretical and actual values as they understood the real-world concepts of circuits addition to the theories taught in lectures. Another student stated similarly: "The best aspect of these projects was how they took the content or things related to the content (the conflict mineral paper specifically) we learn about and applied/related it to real world things that weren't entirely based in theory or something the textbook covers. It made me think about the material in different ways." One student was happy that the research projects were not limited to documenting, but also improved their presentation skills. Namely, "The best part of these projects were the research to different subjects and areas related to what we were learning in the course. Also, I found it great that we the assignments did not have to only be presented in a document but we also had to work on our presentation skills."

5.1.2. Self-Confidence. Some students gained confidence about the circuit concepts and experienced an excitement for learning while working on these projects. A student mentioned: "I enjoyed that these projects showcased real life applications of circuits. This helped me to better understand the importance of these concepts." Another student said: "They were more on the side of practical research than theoretical calculations which is a great way of getting students to realize their potential in researching things on their own by realizing how easy it is to do so."

5.1.3. Preparedness for future. As they improved their skills and knowledge through these projects, they also commented that the ENGG 225 project helped them be prepared for the engineering world when they start their careers: "The best aspect of the all projects was the research component. It helped me to learn about new and different things like the conflict minerals, innovation in electrical energy and the main purpose of power ratings. It was a great way to let the students know about different things happening in the world of electrical engineering."

5.1.4. Deeper Knowledge. This was one of the most common themes. Most students confirmed that they gained deeper knowledge while participating in these projects: "They did help me gain a deeper understanding of the course material, by making me think about the applications of the material more thoroughly than I would have by just doing practice questions." Students were excited to learn the material that normally would not have been taught in lectures. They understood how a broader knowledge could more closely connect them to this field of electrical engineering. Another student added, "[the ENGG 225 projects] weren't entirely based in theory or something the textbook covers. It made me think about the material in different ways."

5.1.5. Analytical skills. Students improved their critical thinking and creativity as they analyzed electricity measurements for the projects. For instance, one student said: "specifically with the 3rd project, having to analyze the power, current, and voltage ratings without clear instructions on how to do it greatly improved my understanding of that part of AC circuits."

5.1.6. Fair Competition. These projects have also provided a sense of academic integrity and fair competition as student tried reaching a solution by themselves. One student stated: "I think projects are perfect because there's no way anyone can cheat on them. A project let's say where a student presents how they are solving a circuit problem or analyzing a circuit is both hard to cheat on and a great way of getting the student to really understand what they're doing."

\subsection{Relatedness}

The need for relatedness refers to students' experiences of positive and mutually satisfying relationships, characterized by a sense of closeness and trust [12]. Students feel connected and experience a sense of belonging, which will boost their motivation and positively effect their studies.

5.2.1 Sense of Belonging. Projects being more connected to the practical world helped the students feel like they belonged in or that they're a part of the electrical engineering world. For instance, "These projects related ENGG 225 to everyday life, making the projects intriguing to write and gave us a better understanding of the electrical engineering world." They better understood the electrical engineering contexts and felt more motivated toward their learning process.

\subsection{Autonomy}

Autonomy refers to students feeling free to engage in their learning and initiate their actions. In other words, it is the need for some level of control over their activities [13], which will lead them to willingly devote their time and energy to their studies.

5.3.1. Self-Directed Learning. Students improved the skills that helped them be in control of their own learning and they discovered their own potential in research. One of them said: "They [projects] were more on the side of practical research than theoretical calculations which is a great way of getting students to realize their potential in researching things on their own by realizing how easy it is to do so." Another student felt similarly, "They [projects] did help me gain a deeper understanding 
of the course material, by making me think about the applications of the material more thoroughly than I would have by just doing practice questions. Specifically, with the $3 r d$ project, having to analyze the power, current, and voltage ratings without clear instructions on how to do it greatly improved my understanding of that part of $A C$ circuits." By willingly putting more effort and time into their education, they took control of their own learning.

5.3.2. Freedom of Choice/choice of independent learning. Students appreciated when they were given the freedom to choose a topic of their own interest for one of the projects: "These projects related ENGG 225 to everyday life, making the projects intriguing to write and gave us a better understanding of the electrical engineering world. As well, project 2 was quite open ended, giving us the freedom to write it on a topic we are interested in. I think the projects were a great way to replace the in-class labs." Similarly, another student said: "Leaving them open ended is great too, like in project 2, let the student pick the thing they want to talk about or tinker around with and present their findings." They were encouraged and motivated by the freedom to choose their topic.

5.3.3. Self-Advocacy. Another common theme was self-advocacy. Through this survey, some students expressed their thoughts on what changes will work best for their own learning. Some students provided feedback on how to improve these projects for better learning outcomes. One student commented: "I feel that these projects should be kept as is or expanded on. I say this because it was not that hard for me to complete the projects, but I feel like they should also be more focused on a particular subject like the first project. And it can also be expanded on by focusing on individual projects on other elements in circuits such as capacitors or inductors." Another student had similar views "It is typically easier to apply course concepts in labs, but a well-organized project can do the same thing. Labs could also be simulated online as another potential substitute." Furthermore, a student also said, "It can be expanded a bit to like in parts and more explanation as I think some projects have a lot of information on it and fitting your idea in 2 pages can be a bit hard."

\section{DISCUSSION AND CONCLUSIONS}

The self-determination theory shows us how to support student motivation through fostering competence, relatedness, and autonomy. In the CURE project in ENGG 225 in Summer 2020, the mini-projects were created to foster these. Topics like Conflict Minerals in capacitors were used to help students connect with the real world without deviating from the technical contents of the course. From their freshman year, the students will understand how social responsibilities are as important as the technical contents of the new inventions. The projects on innovative electrical engineering stories or social causes related to the course will not only improve students' technical knowledge, but also bring social considerations to the focus.

Activities related to the course content helped students visualize and contextualize the lecture content. It broadens their understanding and their interest toward the course as they enjoy participating in such activities, which will keep them focused throughout the course and enhance their skills and knowledge in the subject.

The 3rd project on Power, current, and voltage ratings of household items helped the students understand rated values of real objects and what those values mean from the electrical perspective. Rather than passively listening to lectures, the students discover the knowledge themselves when they actively engage. Confidence, competence, and connection with the course is enhanced when they are practically involved, motivated and engaged with the contents.

All of the above increased the students' intrinsic motivation to study and improved their learning outcomes. For this course, the CURE project served as a replacement for hands-on labs that were cancelled due to COVID-19 pandemic but they may become a permanent fixture of future offerings even after the pandemic. CURE projects can be a strong supplement to engineering science courses with a heavy technical load to provide context and intrinsic motivation for the students. The additional workload for the instructor includes design and evaluation of the projects. The projects can be repeated over multiple offerings without any significant changes, which may be an incentive to take on the initial workload.

\section{References}

[1] N. Hensel, Course-based Undergraduate Research: Educational Equity and High-impact Practice. Sterling, VA: Stylus Publishing, LLC., 2018.

[2] N. McRae, "Experiential learning at Waterloo: building quality EL to prepare students for the future of work and learning," Retrieved from https://uwaterloo.ca/centre-for-teachingexcellence/sites/ca.centre-for-teachingexcellence/files/uploads/files/waterloo_exl institute $n$ orah.pdf

[3] Deci, E. L., \& Ryan, R. M. (2008). Self-determination theory: A macrotheory of human motivation, development, and health. Canadian psychology/Psychologie canadienne, 49(3), 182. 
[4] Yu, Lin, and Ashley Weleschuk. University of Calgary, 2019, Examples Of Course-Based Undergraduate Research Experiences.

[5] Budiman, R. Arief, and Z. H. (Ryan) Zheng. "Making Undergraduate Research Experience More Productive." Proceedings of the Canadian Engineering Education Association (CEEA), 2018, doi:10.24908/pceea. v0i0.13050.

[6] Lord, Susan M, et al, "Teaching Social Responsibility in a Circuits Course". Proceedings of the American Society for Engineering Education (ASEE), 2018.

[7] Beyette, Fred and Davis, Karen and Caffery, James. "A Multi-Faceted First Year Electrical and Computer Engineering Course". Proceedings of the American Society for Engineering Education (ASEE), 2001.

[8] Theories of Motivation (2012). In Organizational Behavior v.1.1. (2012) Saylor Academic. Retrieved February $\quad 9, \quad 2020 \quad$ from https://saylordotorg.github.io/text organizationalbehavior-v1.1/s09-theories-of-motivation.html
[9] Reeve, J. (2002). Self-determination theory applied to educational settings. In E. L. Deci \& R. M. Ryan (Eds.), Handbook of self-determination research (p. 183-203). University of Rochester Press.

[10] Ryan, R. M., \& Deci, E. L. (2000). Self-determination theory and the facilitation of intrinsic motivation, social development, and well-being. American psychologist, 55(1), 68.

[11] Braun, V., \& Clarke, V. (2006). Using thematic analysis in psychology. Qualitative research in psychology, 3(2), 77-101

[12] Niemec, C.P., \& Ryan, R.M. (2009). Autonomy, Competence, and relatedness in the classroom: Applying self-determination theory to educational practice. Theory and Research in Education, 7(2), 133144

[13] Irvine, J. Self-determination theory as a framework for an intermediate/senior mathematics preservice course. Journal of Instructional Pedagogies, vol 22, p1-p27 